\section{NOTAS SOBRE LA FIESTA Y LA REPRESENTACIÓN TEATRAL EN LA SEMANA SANTA DE SANTA MARÍA DE TONANTZINTLA}

\author{
OCTAVIO RIVERA KRAKOWSKA
} este tema, dedicados sobre todo a las condiciones de representación en los Siglos de Oro y a figuras destacadas de este período como González de Eslava y Sor Juana Inés de la Cruz. Sus estudios se han orientado asimismo hacia teatro mexicano contemporáneo. Ha sido Presidente de la Asociación Mexicana de Investigación Teatral $y$ ahora es editor de su revista, Investigación Teatral.

\title{
RESUMEN
}

Santa María Tonantzintla es una población que se localiza a cuatro kilómetros al sur de Cholula y a doce kilómetros al oeste del centro de la ciudad de Puebla. Tonantzintla debe su fama a su templo principal dedicado a la Purísima Concepción de Maria, «Santa Maria Tonantzintla», cuyo interior, de pequeñas dimensiones, es dueño de una de las muestras barrocas mas exquisitas y extraordinarias en México de lo que se puede denominar, según algunos especialistas, arte mestizo.

En Tonantzintla, como en muchas otras poblaciones en el país, la celebración de la Semana Santa es una de las mas importantes del calendario festivo. Parte fundamental de la fiesta religiosa-popular es la representación de la «Judea» que se lleva a cabo desde el Jueves Santo y hasta el Sábado de Gloria. Durante estos tres días, las distintas secciones en que esta dividida la representación teatral, y que van desde la Oración del Huerto hasta la Crucifixión, se intercalan con los actos litúrgicos, los oficios, las devociones y las procesiones, actividades, todas ellas, no exentas de teatralidad, y cuyo desarrollo busca integrar a toda la comunidad en las distintas tareas de la organización, la distribución espacial -y los actos que en ellas se realizan-, su empleo, y, por supuesto, la actitud espiritual.

El propósito de mi trabajo será el de revisar algunas de las características de la fiesta y representaciones teatrales de Semana Santa en Tonantzintla, así como atender a sus relaciones con otras celebraciones de este tipo en México.

\section{FEASTS AND DRAMATIC REPRESENTATION IN HOLY WEEK IN SANTA MARIA TONANTZINTLA}

\section{ABSTRACT}

Santa Maria Tonantzintla is a village located four kilometres south of Cholula and twelve to the west of Puebla city centre. Tonantzintla owes its renown to the main church dedicated to the Most Holy Conception of Mary, 'Santa Maria Tonantzintla'. The church's small interior houses one of the most exquisite and extraordinary baroque examples in Mexico of what could be called, according to come experts, Mestizo art.

As in many other villages around the country, in Tonantzintla the celebration of Holy Week is one of the most important in the festive calendar. A fundamental element of the popular religious festival is the representation of Judea that takes place from Maundy Thursday to Easter

\footnotetext{
Notas sobre la fiesta y la representación teatral en la Semana Santa de Santa María de Tonantzintla
} 


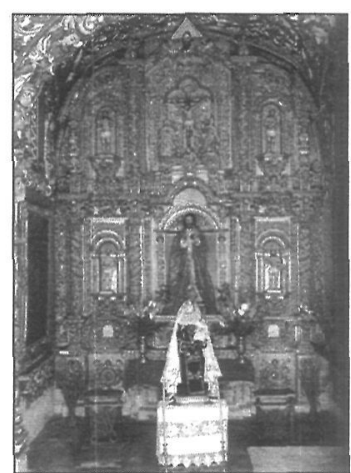

Retablo de la Pasión de Cristo. Santa María Tonantzintla.

Santa María Tonantzintla es una junta auxiliar del municipio de San Andrés Cholula, que es la cabecera municipal. El municipio está ubicado en la región centro-oeste del Estado de Puebla. Tonantzintla cuenta actualmente con una población de entre 3500 y 4000 habitantes. Según Rubial García, la fundación de Santa María Tonantzintla se puede situar hacia 1587 (Antonio Rubial García, Santa María Tonantzintla, un pueblo, un templo, México, Universidad Iberoamericana, 1991, pág. 23) y en "el siglo XVIII [...] Tonantzintla, como todos los llamados pueblos de indios de la región, era ya un poblado mestizo totalmente penetrado por la cultura española, aunque su gente seguía hablando náhuatl y llamándose con nombres indígenas》 (Ibidem, pág. 27). Actualmente, la población, como ocurre en otras muchas comunidades de Puebla, posee apellidos de origen náhuatl. En Tonantzintla, el español es la lengua dominante, al grado que es posible decir que se ho perdido el náhuatl como lengua hablada. La calidad de "poblado mestizo» que atribuye Rubial a Tonantzintla desde el siglo $\mathrm{XVIII}$, es visible en la representación de la Judea, es decir, es una representación mestiza.

\section{2}

Ibidem, pág. 119. Además de libro de Rubial sobre Tonantzintla y su templo pueden verse, entre otros, Pedro Rojas, Tonantzintla, México, Universidad Nacional Autónoma de México, 1956; la antología de textos de Julio Glockner (comp.) Mirando el paraíso. Textos sobre Tonantzintla. Antología, Puebla, Secre-

Notas sobre la fiesta y la representación teatral en la Semana Santa de Santa María de Tonantzintla

Saturday. During these three days, the different sections dividing the theatrical representation from Christ's Prayer in the Garden to the Crucifixion merge with liturgical acts, offices, devotions and processions. All these activities include some form of histrionics and their performance seeks to involve the whole community in different organisational tasks, settings - including the acts carried out therein - work and, of course, spiritual sentiment.

The aim of this work is to look at some celebratory characteristics and theatrical representations from Holy Week in Tonantzintla and study their relation to other celebrations of this type in Mexico.

\section{UNO}

Santa María Tonantzintla es una población que se localiza a cuatro kilómetros al sur de la ciudad de San Andrés Cholula y a alrededor de diez kilómetros al oeste del centro de la ciudad de Puebla en el Estado de Puebla, México ${ }^{1}$. El pueblo de «Tonantzintla», como se le conoce comúnmente, debe su fama dentro y fuera de México, a su templo principal dedicado a la Purísima Concepción de María, «Santa María Tonantzintla», cuyo interior, de pequeñas dimensiones, es dueño de una de las muestras barrocas más exquisitas y extraordinarias en México de lo que se puede denominar, según algunos especialistas,

taría de Cultura del Gobierno del Estado de Puebla, 1995, y el de Luisa Ruiz Moreno, Santo María Tonantzintla. El relato en imagen, México, Consejo Nacional para la Cultura y las Artes, 1993.

3

El Catálogo de ferias y fiestas. Estado de Puebla en lo que corresponde al listado de festividades en San Andrés Cholula, no incluye ninguna celebración durante Semana Santa (Catálogo de ferias y fiestas. Estado de Puebla, Puebla, Secretaría de Turismo del Estado de Puebla [1998], pág. 53). En el caso de Tonantzintla sólo menciona la fiesta patronal (24 de diciembre), aunque Tonantzintla celebra también la natividad de la Virgen. Sin embargo, en la sección introductoria, "Información general», sobre las fiestas en el estado, señala: «La Semana Santa es una fecha muy importante para los fieles que la guardan con devoción. En todos los municipios hay celebraciones religiosas. Empieza el Domingo de Ramos con la bendición de las palmas (Las [sic] hojas trenzadas de diversas y originales maneras). El día más importante es el Viernes Santo cuando se reza el Viacrucis y en algunos lugares se hace la representación de la Pasión de Cristo. Aquí se ven las imágenes ricamente ataviadas, mujeres con incensarios, flores y se oyen cantos entonados por los fieles. En los pueblos indígenas muchas veces es una singular mezcla de las creencias prehispánicas y la religión carólica ya que durante la Conquista los frailes evangelizadores, permitieron que los indígenas conservaran algunos de sus ritos y hoy en día se llevan a cabo en esias fechas ceremonias que datan de la época prehispánica y que no tienen relación con la Semana Santa» (Ibidem, pág. 4). El documento indica que esta información se recoge de "Calendario de Fiestas Populares. SEP. 1988» (Ibidem, pág. 5). El libro La Semana Santa en México. Con la muerte en la cruz incluye el cuadro «Rasgos culturales de la Semana Santa en los estados de la República Mexicana». En el caso del estado de Puebla registra las siguientes actividades: baile, juegos pirotécnicos, música,

arte mestizo. Su decoración y simbología, de acuerdo con los estudiosos, es una de las más ricas y complejas en el país y ha dado lugar a diversas interpretaciones ${ }^{2}$.

En Tonantzintla la celebración de la Semana Santa es quizá la más importante de su calendario festivo-religioso ${ }^{3}$. Esta fiesta incluso posee quizá mayor poder de convocatoria, que la fiesta patronal en honor a Santa María (24 de diciembre) y la de la Natividad de la Virgen (8 de septiembre) ${ }^{4}$. En la celebración intervienen los tres barrios en que se encuentra dividida la población: San Miguel, San Diego y San Pedro5. Parte fundamental de la fiesta religiosa es la representación de la pieza llamada Pasión y muerte del Redentor sóbre

feria, procesiones, alabanzas, alfombras de flores o serrín, bebida ceremonial, danzas de moros, tecuanes, Doce Pares de Francia, vaqueros, palo volador, santiagos, negros $y$ quetzales; $y$ en el listado de «Localidad con representaciones» aparecen: Cuapan, Ahuazote, Ahuehuetitla, Chitla de Tapia, Ortal, San Miguel Xoxtla y Xicotepec de Juárez. No hay mención, por lo tanto, ni a Santa María Tonantzintla ni, en todo caso, a San Andrés Cholula (Sonia Iglesias y Cabrera, Leticia Salazar Cárdenas y Julio César Marlínez Gómez, La Semana Santa en México. Con la muerte en la cruz, México, Consejo Nacional para la Cultura y las Artes, 2002, pág. 102).

\section{4}

De acuerdo con Rubial, un documento de 1790 señala «[...] que los 144 tributarios que poseía Tonantzintla colaboraban en la celebración de casi todas las fiestas dedicadas a la virgen María. Aunque la advocación del patronazgo de la iglesia era la Inmaculada Concepción, esta festividad no tenía una relevancia especial, pues se le celebraba con el mismo boato que a la Asunción de María, a Nuestra Señora de la Candelaria, a Nuestra Señora de la Encarnación, a Nuestra Señora de los Dolores y a las vírgenes de los Remedios y de Guadalupe. Al parecer todas estas fiestas marianas tenían la misma importancia [...]», y añade que a fines del siglo XVIII, «[...] después de doscientos años de vida, Tonantzintla seguía siendo un pueblo fuertemente cohesionado y profundamente unido bajo su cuerpo de república, con sus tierras comunales y alrededor de una organización religiosa centrada en el culto a la virgen María. De ella el pueblo esperaba la fertilidad de sus tierras y de sus mujeres $y$ a ella ofrendaba las primicias de sus cosechas. En su honor fue que construyeron uno de los templos más hermosos que posee nuestro país» (Rubial García, op. cit., póg. 35)

5

Cada barrio posee una capilla dedicada a su santo patrono y se edificaron posiblemente entre 1750 y 1775 (lbidem, pág. 41). 
la Pasión de Cristo a cargo de la «Corporación de la Judea». La representación se inicia el Jueves Santo y concluye el Viernes Santo. Durante estos dos días, las distintas secciones que componen la representación teatral van desde la Oración del Huerto hasta la Crucifixión, y se intercalan con los actos litúrgicos, los oficios, las devociones y las procesiones, actividades, todas ellas, no exentas de teatralidad, y cuyo desarrollo busca integrar a toda la comunidad en las distintas tareas de la organización, la distribución espacial y, por supuesto, la actitud espiritual ${ }^{6}$.

De acuerdo con la tradición popular, las fiestas probablemente se iniciaron entre 1840 y 1860 con el propósito de solicitar la ayuda divina para detener las epidemias que mermaban a la población ${ }^{7}$ y, en el periodo que corre entre 1908 y 1912, hubo un año en que se suspendieron. Los lugareños atribuyeron a este hecho una gran sequía y la pérdida de la cosecha. Desde de entonces, la fiesta se lleva a cabo año con año ${ }^{8}$.

\section{DOS}

Las fiestas de la Semana Santa en Tonantzintla están concebidas de modo que, como he dicho, participe toda la comunidad, al mismo tiempo que se tratan de ocupar todas las calles y los recintos sagrados propios de sus tres barrios. La participación de los tres barrios es de enorme importancia. El número tres es constante en muchas de las actividades que se desarrollan, así como en las formas de organización. Para estas tareas, así como la coordinación y ejecución general de las festividades de Semana Santa, se nombra anualmente, el primer día de enero, una "Directiva General» conformada por el Fiscal Mayor (Presidente), el Teniente (Secretario) y el Cera Mayordomo

(Tesorero). Cada uno de ellos debe proceder de cada uno de los barrios y estar presentes en todos los actos litúrgicos que forman el cuerpo principal de la celebración piadosa.

Esta «Directiva» acuerda comisiones con la presidencia auxiliar y los vecinos. Entre ellas, y en relación con la representación teatral, la presidencia auxiliar debe encargarse de la instalación de tres «templetes» (tarimas), una enorme lona que, a manera de techo, cubre el espacio frente a la capilla de San Pedro en donde se levantan los «templetes» para las escenas del juicio; así como de la iluminación de esta zona, ya que gran parte de la representación tiene lugar la noche del Jueves Santo. En cuanto a los vecinos, una de las comisiones más importantes es la que se compromete en la construcción y decoración del «Huerto» en donde tienen lugar los episodios teatrales de la «Oración» y el «Prendimiento».

La «Corporación de la Judea» es la responsable de la representación teatral. Realiza su tarea de manera paralela con la «Directiva», acuerdan entre sí la realización de la misma, la fecha de inicio de los ensayos, y los días y el horario en que pueden tener lugar, pero no depende de ella para la toma de decisiones en relación con los distintos aspectos de la representación. La "Corporación de la Judea» recibe de la «Directiva General» el apoyo económico para el alquiler del equipo de sonido, la alimentación de los actores durante el tiempo que dura la representación y la compra o alquiler de algunos otros implementos que puedan ser necesarios. La «Dirección» de la "Corporación» se encuentra formada por tres personas: Presidente, Secretario y Tesorero, representantes de cada uno de los barrios. Cada uno los miembros de la «Dirección» de la «Corporación» tiene un suplente, que toma su lugar en caso necesario.

gas, Breve historia de Puebla, México, El Colegio de México - Fondo de Cultura Económica, 2001, pág. 167).

8

Es posible que la suspensión en aquel año se debiera a la situación política por la que pasaba el país, y el Estado de Puebla, en aquellos momentos. A partir de 1908 se organizaron los primeros círculos políticos de la entidad producto de la apertura del presidente Díaz a este tipo de agrupaciones en vista de las futuras elec- ciones de 1910. En la ciudad de Puebla, los movimientos en contra de la reelección, y de Díaz, fueron intensos. El éxito popular de la visita de Madero a Puebla en 1910 se revirtió en contra de sus partidarios en severas y violentas represiones que vivieron momentos álgidos con los asesinatos de los hermanos Serdán el mismo año. Los levantamientos populares se multiplicaron $y$, con la llegada de Madero a la presidencia de la república en 1911, las fuerzas zapatistas, en contra de Madero, contro-

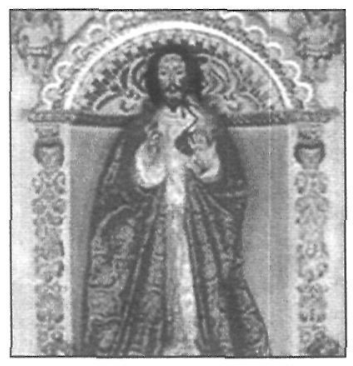

Detalle del Retablo de la Pasión de Cristo (figura empleada en la representación la Pasión y muerte del Redentor).

laron el sur del estado y establecieron un gobierno alterno al oficial. «Este gobierno zapatista adquirió tanta fuerza en la entidad que pudo mantener sitiada a la ciudad de Puebla desde marzo hasta diciembre de 1912 y en algunas ocasiones estuvo a punto de tomarla. / La situación que prevaleció de hecho en todo el estado a lo largo de 1912 afectó severamente su economía. Se redujo la producción agropecuaria en virtud de que una cantidad importante de tierras se dejó de cultivar y de que varias haciendas y ranchos ganaderos fueron saqueados; disminuyó la producción indusirial, sobre todo la textil, por las condiciones irregulares que prevalecieron en el abasto de insumos y en la operación misma de las fábricas, en las que los conflictos que se iniciaron en diciembre de 1911 tuvieron importantes secuelas. El comercio quedó dislocado porque el gobierno del estado no podía garantizar la seguridad en los principales caminos. Las vías del ferrocarril y las líneas telegráficas sufrieron varios atentados y los servicios no pudieron restablecerse al instante por la situación que prevalecía. La generación de energía eléctrica disminuyó y se experimentó una fuerte escasez de mano de obra en la agricultura, la industria y las actividades extractivas. La fuga de capitales se acentuó a medida que pasaban los meses sin que el gobernador pudiera controlar la situación» (Ibidem, págs. 302-303).

Notas sobre la fiesta y la representación teatral en la Semana Santa de Santa María de Tonantzintla

$\overline{\text { OCTAVIO RIVERA KRAKOWSKA }}$ 


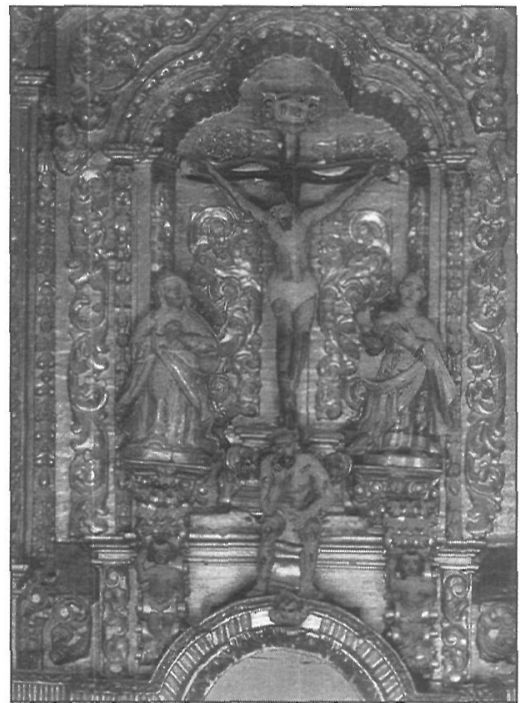

Detalle del Retablo de la Pasión de Cristo.
El Presidente ejerce su cargo durante tres años, debe formar parte de la «Corporación» y es elegido por sus miembros: los actores y el personal técnico. La responsabilidad de la «Dirección» de la «Corporación» es la de proceder a la realización de la representación y coordinar todos sus aspectos estéticos y técnicos. $\mathrm{El}$ «Presidente» tiene la facultad de hacer las modificaciones en la representación que considere pertinentes, particularmente las que atañen a mejoras en el espectáculo: revisión del texto que se interpreta ${ }^{9}$, cuidado del vestuario de los actores ${ }^{10}$, y de las «vistas» (los decorados de los «templetes» $)^{11}$.

De cinco años a la fecha, el Domingo de Pascua, una vez que las actividades han concluido, los miembros de la «Corporación» se reúnen y se hace un informe. En esa ocasión se abre la convocatoria para la sustitución de los actores que han cumplido con su tarea, de acuerdo con la norma, durante los tres años para los que se comprometen para representar a un personaje. En caso de que alguna persona decida suspender su participación, aun cuando no haya cumplido con el tiempo reglamentario, se ofrecen los papeles vacantes. La respuesta de la comunidad es entusiasta y, en caso necesario, se abre un periodo para la selección de los actores ${ }^{12}$.

Las tres personas que forman la «Dirección» deben estar presentes en todas las fases de la representación, al cuidado de que todo se desarrolle con normalidad dentro de lo establecido y atentos a las necesidades de los actores. Darles agua, por ejemplo, si tenemos en cuenta que hay secciones que pueden llegar a durar alrededor de tres horas y que los actores están todo el tiempo sobre el escenario. En relación con esta tarea, es normal ver a los miembros de la «Dirección», entrar, salir o dialogar en escena con los actores, durante la representación. Las «vistas» de los «templetes» deben ser retiradas por los miembros de la «Corporación» inmediatamente después de que terminan las últimas escenas que los ocupan, a lo que les sucede el desmontaje de los «templetes», tarea de la junta auxiliar del ayuntamiento. El objetivo es dejar de nuevo libre la calle en donde todo esto ha sido instalado, y seguir a la procesión que ha salido de la iglesia de San Pedro y terminará frente a la explanada de la iglesia de Santa María. En el trayecto hasta este último sitio, la procesión se detiene en dos ocasiones: una en el templo de San José y otra en el de San Diego. En cada una de ellas tienen lugar una de las «caídas» En Santa Clara Ocoyucan se registra la representación de la Pasión de Cristo /Catálogo de ferias y fiesias..., op. cit., pág. 46). Por su forma literaria el texto, al cual sólo he tenido acceso mediante la representación, podría ser una elaboración de fines del siglo XIX o de principios del XX, con correcciones y adiciones resultado de sus formas de transmisión y de las adaptaciones a que ha estado sujeto a través del tiempo. El título remite al nombre de uno de los tres misterios del Rosario, los «misterios del dolor». No es claro si desde las primeras representaciones en Tonantzintla ya se decía un texto y si, en todo caso, erc el mismo que se dice hoy. En la representación de la Pasión en Iztapalapa -una de las más difundidas y estudiadas en México, y que se iniciaron hacia 1833 (Adriana Luna Parra (coordinación general), Semana Santa en Iztapalapa, México, Departamento del Distrito Federal - Delegación Izłapalapa, Universidad Autónoma Metropolitana-lztapalapa - El Juglar, 1992,

Notas sobre la fiesta y la representación teatral en la Semana Santa de Santa María de Tonantzintla

$\overline{\text { OCTAVIO RIVERA KRAKOWSKA }}$

pág. 227), fecha alrededor de la cual se supone comenzaron las fiestas de Semana Santa en Tonantzintla-, los textos provienen de adaptaciones de la novela de Enrique Pérez Escrich (1829-1897) El mártir del Gólgota y de Los cuatro concilios para la celebración de las tres caídas de Semana Santa, editado por Antonio Vanegas Arroyo, entre fines del siglo XIX y principios del XX (Iglesias y Cabrera, op. cit., págs. 187188). La representación en $(z-$ tapalapa introdujo estos textos hacia fines del siglo XIX. Algo similar podría haber ocurrido en el caso de Tonantzintla. De acuerdo con los informes sobre Tonantzintla, como he dicho, las fiestas de Semana Santa se iniciaron en la primera mitad del siglo XIX, lo cual no implica que desde un principio hubiera habido representación teatral. El «Presidente» de la «Corporación» puede incluir textos, eliminarlos, reducirlos. En 2005, por ejemplo, el texto de Nicodemus, que anteriormente duraba cerca de una hora, se redujo. La longitud del texto y el momento en que se decía (en la madrugada) no retenía la atención del público quien prefería retirarse. Tecuanhuey considera que el año entrante se recortaran otros textos, pues la gente quiere ver "acción» y que cuando algo se recorta o elimina hay que incluir otras acciones y personajes que enriquezcan la obra.

\section{0}

Cada actor es dueño de su propio vestuario, el cual manda a hacer y paga. El traje se hace de acuerdo con las instrucciones que recibe de la «Corporación»y, en principio, debe corresponder al tipo de personaje, su rango social y la comunidad cultural a la que pertenece de acuerdo con la historia representada. Hay una intención de reproducción histórica del traje, aunque es posible observar la inventiva personal en la recreación de los modelos. Cada año se intenta que el personaje enriquezca su vestuario, mediante mejores telas y adornos según corresponda.
11

Las «vistas» son el único objeto que forma parte del acervo material de la "Corporación».

12

Cuando hay más de una persona que desea representar un papel se hace una selección para elegir al mejor. Para la selección, los aspirantes reciben los textos para que los memoricen y los representen en una especie de "audición». Sobre ello se hace la selección. La edad promedio de los actores en la actualidad es de entre 25 y 30 años. Antes los papeles eran representados por personas de más de 35 años. Tecuanhuey opina que la negativa de personas mayores para participar se debe a cierta "timidez». Anteriormente los papeles eran representados por la misma persona durante más de tres años. La presidencia de la «Corporación» decidió, hace aproximadamente seis años, que los actores representaran un papel por un máximo de tres años. Este cambio se implementó con la intención de atraer a más espectadores. Cuando una persona interpreta un papel por primera vez, la memorización debe empezar en octubre del año anterior. Los ensayos generales de la representación se inician el Miércoles de Ceniza de cada año. En los ensayos se cuida particularmente lo referente a «encajonar», que consiste en que cada actor sepa cuando es su turno para intervenir en la obra. Se supone que los actores deben llegar a los ensayos con su papel aprendido pues desde octubre se han comprometido para la representación. En principio, el reparto es básicamente el mismo, durante tres años, aunque por supuesto, como he dicho, puede haber cambios anuales. Los cambios de acuerdo al nuevo reglamento se hicieron también para que más miembros de la comunidad tengan la oportunidad de participar de forma activa en las representaciones; por otra parte, son ellos, quienes tienen preeminencia en la representación de los papeles. 
que señala el Vía Crucis. La última caída, la tercera, y la crucifixión se representan en la explanada frente a Santa María.

\section{TRES}

\section{Las fiestas de Semana Santa en Tonantzint-} la se inician el Domingo de Ramos y terminan en las primeras horas del Domingo de Pascua. La representación teatral tiene lugar el Jueves y el Viernes Santos ${ }^{13}$.

Jueves Santo. A las siete de la mañana se empieza a rezar el Rosario, se hacen plegarias y cantos. La imagen del Sagrado Corazón de Jesús, talla de madera colocada sobre andas, es venerada por los doce apóstoles representados por jóvenes de Tonantzintla. La expresión de la imagen es dolorosa y sus brazos están extendidos hacia el frente. Sobre ellos durante esta fase de la celebración se deposita una rosa de color rojo. La imagen viste de morado y lleva una gran capa de brocado de color hueso con dibujos abstractos en morado y oro. Para la tradición piadosa de Tonantzintla la imagen es milagrosa y forma parte del tesoro artístico de la iglesia. Durante todo el año, está colocada en el «Retablo de la Pasión». Esta imagen es extremadamente im-

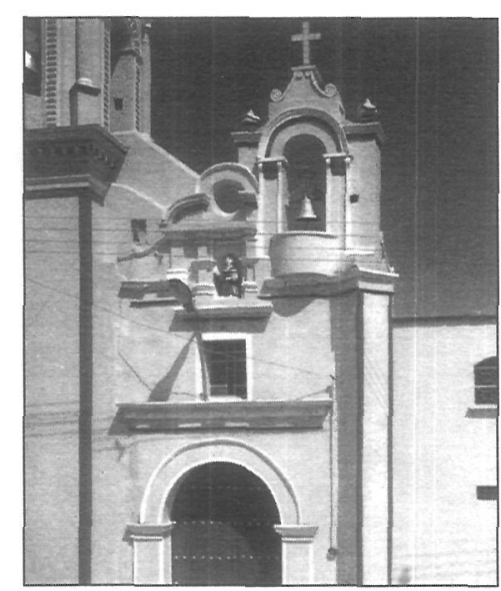

Ermita de San Diego, Tonantzintla.
13 Antes, a partir del Miércoles de Ceniza, los vecinos, frente a sus casas, suelen adornar el piso de la banqueta, todos los viernes hasta el último antes del Viernes Santo, con hileras de pequeños manojos de flores como ofrenda devota. Es común que se empleen "pensamientos», pequeñas flores del litúrgico color morado de los ornamentos de cuaresma y las celebraciones de la Semana Mayor. El Domingo de Ramos, los mayordomos de cada uno de los tres barrios salen muy temprano por la mañana hacia las tres localidades más importantes del municipio de San Nicolás de los Ranchos (a $28 \mathrm{~km}$ de la Ciudad de Puebla) que se encuentran en las faldas de los volcanes Popocatépell e Iztaccíhuatl: San Nicolás de los Ranchos, Santiago Xalitzintla y San Pedro Yancuitlalpan, en donde una buena parte de su territorio está formado por extensos bosques de pinos. Gran cantidad de ramas de una de sus variedades, conocida en México como "ocote», son las que se cortan y sirven para elaborar las "enramadas" («sombras»), techos que se colocan en el atrio de los templos en Tonantzintla entre la entrada principai de la iglesia y la puerta de acceso al atrio de modo que comunican una puerta con la otra; $y$ para armar los «ramilletes». La visita por parte de las autoridades de Tonantzintla, y su propósito, se comunica al municipio de San Nicolás de los Ranchos desde octubre del año anterior al de la fiesta y el día de la visita se les llevan regalos. La visita en el Domingo de Ramos a estas comunidades termina alrededor de las cuatro de la tarde. Los troncos de "ocote», con los que se levanta la estructura que soporta las ramas frescas del mismo árbol, se tienen de tiempo atrás. Las «sombras» se componen, además, de hojas de palma. Contar con estas últimas es responsabilidad de los "Mandones» quienes las llevan a Tonantzinta desde Acatlán - Atencingo, localidades al sur del estado de Puebla. Las hojas de palma, a diferencia de las ramas de "ocote», se trasladan envueltas en papel por ser más delicadas y, quizá, por tener una función más cercana a los actos litúrgicos. Además de ser usadas en la decoración de las «sombras», una parte de las palmas es bendecida durante la fiesta del Domingo de Ramos - día en que se hace una procesión con la imagen de San Ramitos-, y forman parte de las insignias que caracterizan a los jóvenes que representan a los doce apóstoles, quienes las usan en algunos de los actos litúrgicos, así como en parte de la representación. Las palmas se dejan en la iglesia después de la procesión del domingo. El Martes Santo, la hoja de la palma es tejida personalmente por su dueño. Este mismo día se adornan $e$ instalan, junto a los muros del templo, los doce «ramilletes», fuertes y altos troncos de "ocote», en el interior de la iglesia de Santa María, entre el frente de la capilla mayor y la entrada a la iglesia. Los «ramilletes» están cubiertos de ramas de "ocote» y hojas de palma. A los que están junto a la capilla mayor se les cuelgan jaulas con palomas, cuyo canto anuncia el tiempo de la muerte de Jesús. A cada barrio le corresponde la colocación y adorno de ocho de los 24 «ramilletes»: cuatro por cada barrio dentro y fuera de la iglesia. Por tradición, los primeros cuatro «ramilletes» más cercanos a la capilla mayor del templo, dos de cada uno de los lados de la nave la de la pequeña iglesia, le corresponden al barrio de San Miguel, le siguen, los cuatro del barrio de San Diego y junto a la puerta de entrada de la iglesia se instalan los del barrio de San Pedro. La iglesia de Santa María Tonantzintla está en el barrio de San Diego, aunque por ser la iglesia mayor de la comunidad no pertenece a ningún barrio $y$, por lo tanto, todos los habitantes de la población se encargan de cuidar la iglesia y sus alrededores. La comisión encargada de levantar los «ramilletes》 debe ofrecer una comida a todos quienes participan en e trabajo. Al centro de la nave de la iglesia cuelga horizontalmente el "cielo»: un enorme marco de madera adornado por una cortina elaborada con hojas de papel de china de color morado. De él, penden frutas nafurales: piñas, sandias, mameyes, melones chinos, racimos de plátanos, el fruto del coco, grandes obleas de colores: violeta, amarillo, rosa, blanco, y enormes "piñas» del pino. El Miércoles Santo, en el atrio, se levantan y adornan los doce «ramilletes» que soportan la «sombra». La "sombra" se pone el Viernes de Dolores en todas las iglesias de la población a excepción de la de Santa María. Su orden es el mismo que se ha seguido dentro de la iglesia: junto a la entrada al templo estón los de San Miguel, después los de San Diego y a la entrada al atrio los de San Pedro. El sitio que ocupan los cuatro «ramilletes» de cada barrio, dentro y fuera de la iglesia, parece obedecer a viejas discordias entre los barrios en relación con las preeminencias econó- micas y sociales y su importancia en la evolución histórica de la ciudad. Por tradición, la preeminencia la tiene el barrio de San Miguel. Este orden de cercanía respecto de la capilla mayor también se sigue en el que ocupan quienes representan a los apóstoles cuando se encuentran fuera o dentro de la iglesia. De la "sombra», en el atrio, cuelgan frutas naturales: piñas, mameyes, las «piñas» del pino. De acuerdo con la tradición, las frutas deben ser naturales, aunque este año hubo algunos adornos de papel de china imitando frutas: piñas, racimos de uvas, manzanas. Los escalones de acceso al atrio, cuyo pórtico de entrada está formado por un muro con dos arcos, se cubren de pétalos de flores. Así, el aspecto plástico, odorífero (el "ocote") y sonoro (el canto de las palomas y el Viernes Santo el de un gallo), sobre todo el del interior del templo, impresiona y conmueve al visitante. El espacio recargado de la decoración vegetal cubre una parte de la riqueza decorativa de los muros del templo, de manera que parece que se ha entrado a un bosque. El Jueves Santo un lienzo enorme de color morado, el «luto», oculta a la vista la capilla mayor. Sobre los muros laterales de la nave se encuentran visibles sus cuatro retablos permanentes. Cada uno de estos altares está decorado de manera sencilla con carpetas de papel picado, rosetones de palma tejida, pequeñas macetas de latas cubiertas por papel de china de color morado con chía germinada. La capilla de crucero, a mano izquierda de la capilla mayor, tiene un retablo dedicado a la Pasión de Cristo. La figura principal es un Cristo crucificado, rodea-

do por otras cuatro pequeñas figuras de Jesús en distintos mo mentos de la Pasión. Esta capilla, en Semana Santa, se adorna ricamente con un altar efímero de tres pisos dedicado a Cristo en el Huerto de los Olivos. A los lados de una reproducción litográfica de una pintura de Cristo en oración en el Huerto, que es el objefo principal de este altar. se encuentran doce candelabros de una sola y larga vela blanca que también han sido ornados con rosetones de palma tejida y pequeñas banderas de papel picado de colores oro y plata. El papel picado, tanto el que se encuentra en los altares laterales como el de las banderas, presenta imágenes del cáliz con la hostia o el rostro de Jesús. A los lados de los candelabros se encuentran enormes jarrones cuajados de azucenas. Sobre el piso hay gran cantidad de veladoras en recipientes de vidrio incoloro llenos de aceite. Estas veladoras se prenden el Jueves Santo y se refiran el Viernes Santo. Las veladoras se regresan a sus propietarios. Los miembros 


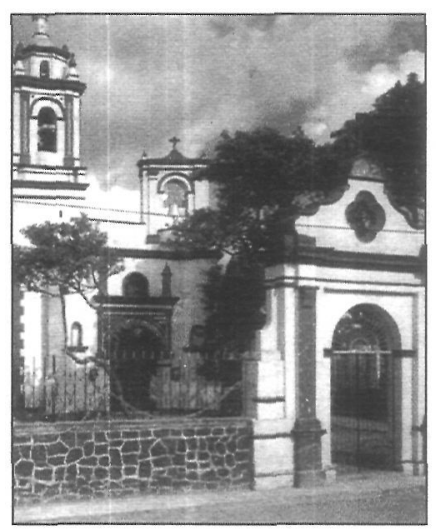

Ermita de San Miguel, Tonantzintla. portante, tanto en la liturgia de las fiestas como en la representación teatral de la cual es de hecho el «actor principal». Desde sus orígenes, la representación teatral de Tonantzintla nunca ha considerado a una persona para que represente a Jesús, aspecto común en otras representaciones de la Pasión en el país, y elemento que también distingue a la de Tonantzintla. El empleo de esta imagen de bulto, utilizada desde las primeras representaciones, desea mantener el carácter sagrado, la fe, el respeto y la solemnidad de la representación.

La imagen se encuentra escoltada, como he dicho, por doce varones -de preferencia solteros- de entre quince y veintiocho años que representan a los apóstoles. Los apóstoles van descalzos y visten alba blanca, capa de color, y una especie de «mantel» blanco doblado en forma triangular y bordado con símbolos de la eucaristía cubre sus hombros. Sobre sus cabezas llevan una corona de espinas entretejida con flores cuyos colores de preferencia podrán ser el morado y el blanco. Estos jóvenes provienen de los tres barrios de la población, cuatro por cada barrio, y su participación, en principio, está sujeta a turno según una larga lista. Los apóstoles pueden distinguirse por llevar capas de tres colores distintos, cuatro por cada color y barrio: azul, morado y rojo, por ejemplo ${ }^{14}$.

La imagen de Jesús (dentro o fuera de la iglesia) ${ }^{15}$ recibe de frente al feligrés. Entre la imagen de Jesús y los apóstoles y la entrada al atrio hay dos columnas formadas, cada una de ellas, por seis mujeres jóvenes, que visten una blusa de color azul marino y pantalón de color hueso. Ellas son las «faroleras» quienes se encargan de llevar un farol cada una de ellas, de las oraciones y los cantos en cada una de las fases de la celebración ${ }^{16}$.

Lavatorio y Última Cena ${ }^{17}$. La misa de la «Institución de la Eucaristía» o «De Lavatorios» se inicia a las tres de la tarde. La conclusión de la misa se enlaza inmediatamente con una representación de la última cena. Para ello se coloca una mesa en donde los apóstoles ocupan sus lugares: seis de cada uno de los lados de la mesa. El sacerdote, todavía como parte del acto litúrgico, representa a Jesús. Cada apóstol recibe un plato, un pan y una copa en donde se le sirve sidra. El acto se celebra en silencio. Los apóstoles cortan una parte del pan y el resto lo comparten con los feligreses. Al terminar la misa, el sacerdote anuncia la representación de la «Corporación de la Judea». Durante la misa se han escuchado flautas y tambores cuyo sonido viene del exterior del atrio. El sacerdote se retira. Se inicia, entonces, la «Búsqueda del Redentor», se escucha la voz de Jesús, a través de un altavoz, con ello se da principio a la representación teatral. El actor que hace la voz de Jesús está oculto, de manera que nunca pueda ser visto.

En tres ocasiones, una por cada barrio, aproximadamente cincuenta jóvenes de edades de entre 10 y 20 años, aproximadamente, que representan al ejército romano, entran al atrio. La idea de las entradas es intimidar a los apóstoles y a Jesús. La llegada al atrio está precedida por tres o cuatro jóvenes a caballo. El ejército entra al atrio y forma una valla para apartar y resguardar a los fieles. La valla está formada por una categoría de soldados cuyo traje «a la romana» se distingue por sus colores blanco y negro quienes delimitan un pasillo con sus lanzas de madera. Por el centro del pasillo entra el resto del ejército haciendo sonar flautas de pico y tambores, estos soldados visten de blanco y rojo. Este enorme contingente está precedido por dos soldados de blanco y negro quienes llevan faroles y cadenas las cuales golpean contra el piso de piedra del atrio. Llegan hasta donde se encuentra la imagen de Jesús a la cual los apóstoles ocultan con las hojas de palma tejidas y adornadas con flores. Los soldados buscan a Jesús pero no lo encuentran. Al finalizar la tercera entrada, Jesús es descubierto. Acto seguido da principio la procesión hacia el «Huerto» ${ }^{18}$.
18

La procesión está encabezada por la imagen en andas de Jesús y es transportada por los doce apóstoles, tras ellos o los lados, dependiendo del ancho de las calles por donde se circula, y

Notas sobre la fiesta y la representación teatral en la Semana Santa de Santa María de Tonantzintla

OCTAVIO RIVERA KRAKOWSKA de la cantidad de gente que acompaña la procesión, marchan las faroleras. El camino de la procesión se encuentra decorado por los habitantes de las casas que dan a estas calles. El camino se adorna y señala con rechos de hilos de pequeños lienzos de papel o plástico picado de colores blanco y morado. Los papeles presentan imágenes de los símbolos de la euca- ristía, imágenes de Cristo, la Virgen de los Dolores o flores. Sobre las paredes de las casas - establecimientos se cuelgan adornos también de papel, palmas, rosetones tejidos de hojas de palma. El piso del camino de la procesión está marcado por flores, pétalos de flores, hierbas aromáticas o aserrín pintado de distintos colores formando distintas figuras Inuevamente las propias de la eucaristía). En algunos tramos, aquellos en donde el camino es de tierra, los vecinos riegan el piso para evitar que se levante el polvo. En el camino de la procesión se visitan las tres iglesias de los tres barrios: 1 San Diego; 2. San Miguel y 3. San Pedro. Se hace una pequeña parada en cada una de ellas. Las iglesias también han sido adornadas, a la manera de la de Santa María, aunque de manera más sencilla: una enramada con hojas de pino y frutas frente a la puerta principal y el marco con frutas que pende al centro de la nave. Las iglesias son pequeñas y no incluyen los «ramilletes» que se ponen en el interior de Santa María. Durante la procesión se alternan las oraciones y cantos de las faroleras - a quienes responden quienes acom pañan la procesión-, con la 
Oración del Huerto. El «Huerto» se construye al nivel del piso y en esta ocasión tenía la forma de una «L». Se delimita con grandes macetas, muchas de ellas con pequeños cipreses, y está techado con una enramada de «ocote». La calle se cierra con este "Huerto» y con un enorme lienzo con una pintura que representa a Jesús en oración y a un ángel que arroja luz sobre él. El ángel que lo consuela, según la versión de San Lucas ${ }^{19}$. La procesión llega al sitio, entra por la parte más larga del pasillo y la imagen de Jesús es colocada como en oración frente a una capilla doméstica y está acompañada de los apóstoles y las faroleras quienes ocupan el espacio frente al lienzo. La imagen no debe darle la espalda a la capilla de San Pedro. En el sitio tienen lugar nuevamente oraciones y cantos.

Traición de Judas y Prendimiento. Cuatro de los apóstoles se separan de la imagen en andas y se sientan en el suelo en el pasillo de la entrada. Forman dos grupos que fingen dormir recargando su espalda sobre la del compañero. Al lugar llegan los soldados romanos y los pretores buscando a Jesús. La imagen en andas es removida del sitio en que estaba y se coloca en la boca del pasillo. Los soldados preguntan quién de ellos es Jesús. El actor que representa a Judas, quien acompaña a los soldados, se acerca a la imagen y la besa. Los soldados deciden acercarse a la imagen pero su paso es impedido por los apóstoles que estaban sentados sobre el piso. Hay forcejeo. Los soldados se acercan a la imagen y se interpone Pedro quien le corta la oreja a Malco. A Judas se le entregan las monedas. En 2005, en toda esta escena se usaron como música de fondo pasajes de la música de la película La pasión de Cristo (2004) dirigida por Mel Gibson. Los soldados se llevan preso a Jesús. Le sujetan en las manos largas cadenas doradas de plástico y le cubren los ojos con un lienzo fino. La procesión se inicia de nuevo y regresa a la explanada frente de la iglesia de San Pedro. El camino se acompaña de cantos, oraciones y música.

\footnotetext{
música solemne que interpreta una banda de doce integrantes compuesta por instrumentos de viento: una tuba, dos saxofones, trombones $y$ trompetas; y percusiones: dos tambores $y$ unos platillos. La última iglesia que se visita es la de San Pedro. De ahí la procesión avanza hacia el «Huerto» instalado aproximadamente a un kilómetro de la última iglesia visitada. Desde Santa María
}

hasta el «Huerto» la procesión dura aproximadamente dos horas. Diez años atrás, la "Oración en el Huerto" y el "Prendimiento de Cristo» tenían lugar veinte metros atrás de la capilla de San Pedro. Como estaba demasiado cerca de los «Pretorios» la gente prefería quedarse en esta zona. Hoy está a la salida del barrio de San Pedro rumbo al pueblo de Chipilo.
Juicio en el Sanhedrín. La procesión llega al frente de San Pedro. Un gran tramo de la calle frente a la iglesia (aproximadamente $50 \mathrm{mts}$.) está cubierto por un enorme toldo a cuyos extremos se han levantado sobre el piso dos tarimas («templetes») de aproximadamente seis metros cuadrados cada una de ellas. En este momento los «templetes» representan el Sanhedrín y, el viernes por la mañana, los Pretorios. El acceso a la superficie de las tarimas se hace por el frente, por escaleras de aproximadamente seis escalones, que ocupan casi todo el ancho del escenario, pero que dejan un espacio libre de aproximadamente dos metros y medio. La cara frontal de ambos escenarios está una frente a la otra. Las tres paredes del escenario de la derecha están cubiertas por cortinas de terciopelo color vino, cuyo borde superior lleva una galera con borlas de color verde olivo. Los cortinajes recuerdan el gusto del siglo XIX. Sobre el escenario hay alrededor de doce asientos entre sillas y sillones, con el respaldo hacia las paredes. El sillón principal, el del centro, está tapizado de terciopelo rojo. A los lados del escenario, al frente y sobre el piso hay dos grandes figuras de águilas de cerámica. El segundo escenario está decorado en un estilo similar al del primero, con cortinas sillas y sillones, pero en este caso los cortinajes son de color azul claro y, en lugar de águilas, hay dos grandes cobras de cerámica.

La imagen de Jesús es transportada hasta el frente del Sanhedrín de cortinas color vino y el juicio da principio. A partir de este momento, y hasta el final de esta primera parte del juicio, que dura aproximadamente tres horas, los apóstoles sostienen en las andas la imagen de Jesús que queda junto al escenario, y a su altura, ocupando el espacio libre de escaleras de la parte frontal. El juicio, pues, se inicia en el escenario de la izquierda. Una segunda escena tiene lugar frente al escenario de la derecha, la de las declaraciones de los cinco «testigos» y termina nuevamente en el escenario de la izquierda. Durante la representación del juicio, los actores emplean micrófonos inalámbricos y las breves intervenciones orales de Jesús, aquí como en todas las escenas en que participa, como antes he dicho, las ejecuta un actor oculto a la vista del público del cual sólo se escucha su voz a través de los altavoces.

De acuerdo con cada uno de los «templetes» que se emplean en esta parte de la re-
19

La decoración del "Huerto» es tradicional aunque trata de ser enriquecida cada año. Desde hace tres años se pone el gran lienzo con la imagen de Jesús y el ángel en el huerto. La colocación de ese lienzo ha sido acordada por los presidentes de las distintas comisiones que se encargan de la fiesta. La forma del huerto en "L» la decidió la familia que aceptó la comisión de realizarlo. Esta comisión puede cambiar cada dos años. 


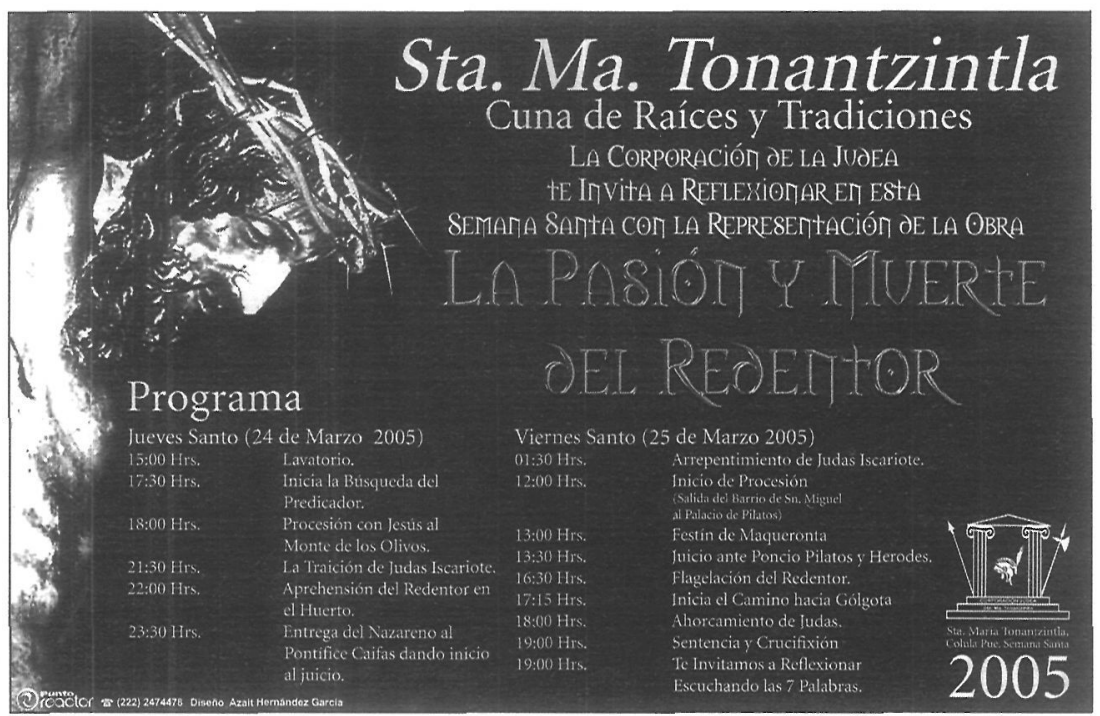

Programa de la Semana Santa de Santa María Tonantzintla 2005.

20

Mientras tanto en el interior de la iglesia de Santa María se han colocado nuevos objetos. Frente al arco de donde pende el «luto» se ha desplegado otra enorme cortina de color negro que sólo cubre la mitad de arriba a abajo del espacio abierto. Esta cortina está adornada con un enorme crucifijo que descansa sobre un cuadrado formado también con pasamanos dorados. Al entrar al templo, se puede ver, entonces, al fondo un paisaje de dos colores: el negro de la primera cortina $y$ el morado de la segunda. Frente a esta última se ha levantado un altar con dos superficies, la de arriba de menor tamaño que la de abajo. Ambas están cubiertas de tela negra y sobre la superior, un enorme crucifijo de madera labrada sostiene la figura de un Cristo de expresión sufriente y piel oscura y manchada, el perizoma de mandil es de brocado color blanco y plata. Al lado izquierdo del crucifijo está una figura de la Virgen de los Dolores y, a la izquierda, una de San Juan Evangelista vestido de blanco con el atributo del cáliz envenenado. En los extremos de esta superficie dos pequeñas y hermosas esculturas de los ladrones, Dimas y Gestas, en sus cruces, completan el cuadro. En los extremos de la superficie inferior dos enormes candeleros sostienen largas velas negras. En la parte superior del «luto» se han puesto dos imágenes

Notas sobre la fiesta y la representación teatral en la Semana Santa de Santa María de Tonantzintla

OCTAVIO RIVERA KRAKOWSKA

presentación, el cuerpo de soldados romanos de blanco y negro, delimita con las lanzas un espacio rectangular frente al escenario, en cuyo interior aguardan los soldados que hacen sonar tambores y flautas cuando se desplazan de uno a otro «templete». El público ocupa de pie el espacio libre que rodea a la valla de soldados. En este espacio abarrotado de gente están quienes atienden la representación, puestos de comida, vendedores ambulantes y la gente que asiste a la especie de feria que se ha formado frente al templo. De este modo, es evidente que no hay silencio para escuchar lo que dicen los actores, quienes compiten con la algazara de feriantes y vendedores. Para la «Dirección» de la «Corporación» esta es una de las secciones más complejas. Se trata de largas escenas en donde un alto porcentaje está formado por monólogos de quienes declaran a favor o en contra de Jesús. A nivel textual,

circulares que representan a la luna, a la izquierda, de gris y con los ojos mirando hacia el cielo y, a la derecha, el sol, en rojo, cuya mirada ve al frente. El dibujo de ambos rostros recuerda el del rostro central de la piedra del sol o calendario azteca. A lo largo del día y hasta el momento en que la procesión regresa al templo, un grupo de doce mujeres adolescentes, las «Magdalenas» vestidas de túnicas y capas moradas y con el cabello largo y suelto, suben, una a una, hasta el pie del crucifijo, al cual se abrazan estáticas, es, sin duda, la sección más demandante para los actores, entre otras razones, por la longitud de los textos.

Entre el inicio de la Misa de Institución de la Eucaristía y el fin de esta parte de la representación, transcurren alrededor de doce horas de actividad constante por parte de quienes participan del festejo. Una vez que termina la primera parte del juicio, la procesión camina hacia la capilla de San Miguel que funge como la cárcel de los hebreos. La procesión avanza tres pasos y regresa dos. El lento retorno busca retrasar el encarcelamiento y coincidir con el amanecer del Viernes Santo. La llegada a San Miguel ocurre alrededor de las cinco de la mañana.

Viernes Santo. Las actividades del Viernes Santo se inician alrededor de mediodía. La imagen de Jesús en andas regresa frente a los «templetes» frente a la iglesia de San Pedro, para continuar con el juicio ${ }^{20}$.

Cristo ante Pilatos. Frente a la iglesia de San Pedro el juicio continúa. Jesús, en las andas, escucha los discursos y veredicto de Pilato. En esta secuencia del juicio del Viernes Santo, además de los dos escenarios descritos anteriormente, se ha levantado otra plataforma, sin decorado, de menor tamaño. Esta superficie se encuentra a la mitad del camino entre las dos anteriores, y a un lado, de modo que no obstruya el pasillo que se forma entre los escenarios que están frente a frente. La plataforma está ocupada por los judíos Onkelos, Caifás y Anás. Los tres escenarios se emplean de modo simultáneo. El de la derecha es ocupado por Pilato y su corte. Para este día el «templete» de Pilato ha sido enmarcado con dos columnas y un tímpano simulando un palacio romano. El de la izquierda representa el palacio de Herodes. Durante el juicio se produce una aparente alteración del orden. Los ladrones que acompañaran al Cristo crucificado roban comida de uno de uno de los puestos efímeros de la pequeña feria y corren a resguardarse en una casa. Los ladrones apenas visten un burdo calzón hecho por un largo lienzo de algodón, su cabello está revuelto y sobre la cara y el cuerpo les han maquillado suciedad y heridas.

El vestuario de los jueces romanos y judíos parece inspirado por los trajes de las imágenes en los templos. Terciopelos, telas de reflejos de oro y plata, capas, cordones con borlas doradas, mantos, túnicas. En esta secuencia del juicio intervienen mujeres, aunque no hablan. Sus trajes son más simples, de colores pálidos, con velos o piezas de tela colgando 
de los hombros que den la impresión de trajes romanos femeninos. Casi todas llevan tiaras de pedrería de las que se usan, en México, para coronar a las reinas de las festividades populares o a las quinceañeras.

Ecce Homo. Al terminar el juicio, a la figura de Jesús se le pone una capa de terciopelo rojo guarnecida de galones dorados. Lleva también una corona de espinas con rayos de plata y la cruz. Se inicia, así, la secuencia del camino al calvario y las caídas.

Camino del Calvario y Caidas. La columna de la procesión se organiza de manera que al frente de la imagen marchen todos los personajes que han tomado parte en el juicio, van con ellos los ladrones. Frente a la imagen marcha el sacerdote del pueblo y tras ella la comunidad $^{21}$. La procesión en esta ocasión está acompañada por un hombre con un pequeño clarín que hace sonar el instrumento cuando la procesión debe continuar. Cada una de las tres caídas se representa simbólicamente con tres paradas: la primera en la iglesia de San José, la segunda en la de San Diego y la tercera en la de Santa María. Al llegar a cada una de las iglesias, la procesión se detiene y el sacerdote sube a un púlpito movible que se pone junto a la entrada principal de la iglesia o, en el caso de Santa María, a la entrada del atrio. Desde allí dirige un sermón a los feligreses ${ }^{22}$. Cuando la procesión está a punto de avanzar desde San José a San Diego, en un antiguo y alto árbol que se encuentra a pocos metros de la capilla en el camino de la procesión, tiene lugar el ahorcamiento de Judas, quien de pronto aparece suspendido de una de sus ramas. Una vez que ha concluido la caída en San Diego, a la imagen de Jesús en andas se le suman otras dos a sus costados: una de la Verónica y otra de la Virgen de los Dolores. Se trata de andas más pequeñas. En los cuatro extremos de las andas de cada figura se levantan largos «ramilletes» de flores ${ }^{23}$.

Antes de que continúe la procesión, entre San Diego y Santa María, se hace espacio en la calle para la representación de una escena sobre el judío errante amonestado por su

\section{1}

El suelo por donde camina la procesión, como en los casos anteriores, se encuentra cubierto por pétalos de flores o aserrín de colores. Hilos de papel picado hacen techos sobre las calles y se compone el adorno de las fachadas de las casas.

madre ${ }^{24}$. La procesión avanza con las figuras hasta llegar a la calle frente a Santa María. La cantidad de gente que se ha reunido hasta este momento ha crecido de manera significativa. Frente a la iglesia se encuentran tres cruces sobre un puente que antiguamente cruzaba un arroyo que hoy ha sido entubado. Sobre las cruces de los costados son colgados los dos ladrones. La cruz central de Cristo permanecè vacía. Un gran espacio frente a la puerta del atrio sobre la calle es delimitado por los soldados romanos. En este lugar aparecen dos soldados romanos a caballo. Ambos se desplazan de un lado a otro del largo pasillo, mientras uno de ellos comunica al pueblo reunido la sentencia que se le dictado a Cristo. Con esto termina la representación de la «Judea» y la procesión. El sacerdote invita a la comunidad a participar en los «Oficios» del Viernes Santo ${ }^{25}$. Al término de los «Oficios» se procede a desmontar el altar efímero levantado frente al «luto». Se retiran las imágenes de la Dolorosa, San Juan, los dos ladrones, los candeleros.

Descendimiento de la Cruz. Una vez que se despeja el espacio de los altares, los apóstoles vestidos sólo con el alba, proceden a bajar al Cristo de la cruz. Ayudados por paños blancos que impidan el contacto directo de las manos con el cuerpo de la escultura, le quitan los clavos que la sostienen sobre la cruz. Esta figura de Cristo parece ser de piel o tela de modo que los brazos están articulados y cuelgan de los hombros cuando se retiran los clavos que los detienen sobre el madero transversal de la cruz. La escultura, del tamaño de un hombre, es bajada con sumo cuidado y depositada en una urna de paredes de cristal. Un grupo de fieles encabezados por un individuo que lleva lo que llaman la «urnita», pequeña caja de vidrio con monedas dentro, inicia una breve procesión con la urna donde reposa la figura de Cristo que ha sido desclavada. Salen de la iglesia y rodean la manzana. Cantos, oraciones, flores y música acompañan la procesión con la que se cierran las celebraciones del Viernes Santo26.

23

La Dolorosa y la Verónica son imágenes pertenecientes a la iglesia de Santa María. Se supone que ambas encuentran a Jesús en el camino al Calvario.

24

En Tonantzintla, el «judio errante» ofende a Jesús pues no curó a su madre. La madre aparece caminando y le dice a su hijo que pudo curarse gra cias a Jesús y le dice que por haber blasfemado contra él su castigo es caminar sin parar hasta el fin de los tiempos. «Una antigua leyenda popular, sucesivamente elaborada en obras literarias de diversos países, se refiere a Ahasvero, zapatero judío, sobre el cual gravita el peso de la maldición de Cristo durante el drama de calvario. Ahasvero tomó parte en el tumulto de la chusma que pidió la liberación de Barrabás en lugar de Jesús; luego lo rechazó brutalmente cuando se apoyó en el muro de su casa al ser conducido al suplicio; en fin, presenció la Crucifixión. Desde entonces el judio errante vaga por el mundo sin detenerse, y así seguirá, según la leyenda, hasta el día del juicio universal» ("Diccionario católico», op. cit., pág. 165).

25

La Misa puede decirse en cualquier día del año, excepto el Viernes Santo.

26

El Sábado Santo, para la Misa de la Vigilia de Pascua, del interior del templo se han quitado los doce «ramilletes» y los adornos de la capilla de la izquierda. La misa se inicia alrededor de las once de la noche. Las luces del atrio y del interior de la iglesia se apagan. En la oscuridad, en una gran tina de aluminio se depositan leños de "ocote» a los que el sacerdote prende fuego. De ese fuego toma la llama para prender un enorme cirio de color rojo y de la lama del cirio los fieles prenden sus propias velas. El sacerdote entra al templo seguido de la comunidad. Aproximadamente la mitad de la misa se lleva a cabo dentro de la oscuridad del templo sólo iluminado por las velas de los fieles. Una segunda parte se inicia cuando después del Credo y como inicio del Ofertorio se abre la «gloria». Las cortinas frente al altar mayor se dejan caer lentamente, se prenden todas las luces, se hacen sonar las campanas y los carillones de la iglesia, se prenden cohetes. Mientras las cortinas descienden de la cúpula, caen pétalos de flores y aproximadamente veinte personas con enormes jarrones colmados de azucenas entran al templo y los colocan en todos los altares. La capilla mayor con la imagen de la dedicación de la iglesia: la Inmaculada Concepción de María, resplandece de luz, oro y flores. El resto de la misa se celebra en el regocijo de la resurrección de Cristo. Es la madrugada del Domingo de Pascua.

Notas sobre la fiesta y la representación teatral en la Semana Santa de Santa María de Tonantzintla

OCTAVIO RIVERA KRAKOWSKA 

de bulto en las procesiones religiosas, en México, uno de los primeros registros de empleo de imágenes en ceremonias no litúrgicas con motivo de la Semana Santa data de 1582 (Fray Agustín Dávila Padilla, O.P., Historia de la fundación y discurso de la provincia de Santiago de México de la Orden de Predicadores, pról. de Agustín Millares Carlo, México, Academia Literaria, 1955, págs. 567-565)
Notas sobre la fiesta y la representación teatral en la Semana Santa de Santa María de Tonantzintla

OCTAVIO RIVERA KRAKOWSKA

\section{CUATRO}

La representación de Tonantzintla, como otras muchas en México, no incluye a un actor que interprete el papel de Jesús, el cual, como hemos visto, es representado por una figura de bulto del Sagrado Corazón de Jesús que forma parte de las imágenes sagradas permanentes del culto en la iglesia de Santa María y que ocupa la parte central del Retablo de la Pasión ${ }^{27}$. El empleo de esta imagen, tradicional desde las primeras representaciones de Semana Santa en Tonantzintla, intenta subrayar el carácter religioso de la representación, el significado solemne de la muerte de Cristo, y hace imposible intentar «ser» Jesús en la representación teatral. Al eliminar, en general, las figuras vivas de miembros de la comunidad para representar figuras sagradas (a excepción de los apóstoles), se evitan también los aspectos truculentos y la devoción popular se orienta hacia la reflexión interior y la concentración en una imagen siempre presente $y$, a su manera, siempre viva en el templo. Se evita, es evidente, llamar la atención, mediante efectos espectaculares de dolor y de sangre.

En este sentido es útil observar que la compasión del público por el sufrimiento de los actores en escena se podría dirigir, en todo caso, hacia los apóstoles quienes cargan por horas las andas con la imagen de Jesús, descalzos y con coronas de espinas y quienes no dicen un solo parlamento. Recordemos además que poder interpretar a uno de los apóstoles implica, de entre todos los papeles, apuntarse en una lista y esperar un turno que puede tardar años en llegar a cumplirse. A diferencia de otros actores que tienen la oportunidad de mantener un personaje hasta por tres años, para quienes interpretan a los apóstoles, la ocasión se presenta una sola y única vez, un solo año. De entre las distintas secuencias de esta representación, aquellas que podrían prestarse a la compasión de los espectadores por el «hecho vivo» serían las del ahorcamiento de Judas y la crucifixión de Dimas y Gestas. Sin embargo, ambos actos se descubren ante el público sólo como imágenes: Judas colgado de la rama de un árbol, los ladrones sobre sus cruces, no hay acciones previas que desarrollen el acto y despierten el morbo del espectador, simplemente aparecen. En la concepción del mundo de la representación no se presenta a la vista, entonces, tampoco la crucifixión de Jesús, cuya cruz frente al templo, entre las de los dos ladrones, destaca por estar vacía, por su color verde, por estar labrada -a diferencia de las otras-, y porque es un objeto de la liturgia que se usa en la misa del Sábado Santo, de manera similar al Cristo que se emplea en la representación.

Otro aspecto sobre el cual conviene hacer algunas observaciones es el que se refiere al espacio escénico. Como antes se ha señalado, las distintas secciones de la representación disponen escenas en los tres barrios de la población. Esta especie de «escenario múltiple» no es privativo de Tonantzintla y se suma a un sistema de raíces medievales empleado en otras poblaciones del país. En el caso que nos ocupa, sin embargo, es conveniente insistir en que la representación teatral parece obedecer a una manera de hacer participe a toda la comunidad en el acto teatral y su sentido religioso. Metafóricamente Tonantzintla, mediante la representación teatral, se transforma en una Jerusalén efímera, en donde cada escena se desarrolla en un sitio específico del pueblo y distinto de los demás: la última cena en el atrio de Santa María, el largo camino por las calles de la ciudad hacia el Huerto de los Olivos; el Huerto en los límites de la población; el Sanherdín y los pretorios frente a San Pedro; la cárcel en San Miguel; la vía dolorosa de nuevo en sus calles; las caídas en San Miguel y San Diego; el monte Calvario en la explanada frente a Santa María. De esta manera, todos los habitantes del pequeño pueblo, y los sitios comunes de su vida cotidiana, quedan incluidos en las solemnidades de la Semana Santa, por las tareas que les corresponde realizar, y porque muchas de ellas se llevan a cabo en las capillas que son el centro espiritual de sus barrios, además de que empiezan y culminan en el corazón espiritual de su ciudad: la iglesia dedicada a Santa María.

Los requisitos para ocupar el cargo de "Presidente» de la "Corporación», sus facultades, las maneras de la organización, la preparación de los participantes, así como la forma y el sentido de la representación son signos, entre otros, de una tradición de representación teatral cuya conformación actual es, efectivamente, por su rigor, el producto de largo tiempo. El «Presidente» y la «Corporación» responden a esta tradición y, al margen de sus derechos, tienen, sobre todo, la responsabilidad de mantener un propósito y ciertas formas que dependen de un aprendizaje obtenido mediante su pertenencia a la comunidad y la observación de sus fórmulas. Creo que no estaría fuera de lugar decir que el «Presidente» de la «Corporación» funge como un «Maestro de Ceremonias» que conoce 
perfectamente los modos de llevar a cabo la representación teatral, que cumple con ellas de la mejor manera posible y que sus «contribuciones» mediante las modificaciones que se introduzcan están comprendidas dentro de las normas de una tradición en donde no hay rupturas, simplemente porque este es un aspecto que no se considera en Tonantzintla.

La representación de la Pasión en Tonantzintla parece responder pues a un esquema fijo, con las variantes propias, cuando se introducen, de una celebración viva que siempre será un proceso y que las admite, en tanto no sugieran modificaciones que alteren su significación y su propósito y que sean, sobre todo, capaces de intensificar la devoción espiritual, el respeto y la solemnidad del acto representado. Las festividades de la Semana Santa en Tonantzintla, incluida la representación teatral, contribuyen al esplendor de la pequeña comunidad -cuyo máximo representante es el templo principal-y confirman su identidad, no obstante su cercanía a las populosas comunidades de San Andrés y San Pedro Cholula y de la ciudad de Puebla, más expuestas a los movimientos de la población flotante y, por lo mismo, a la posibilidad de mayores influjos culturales.

\section{BIBLIOGRAFÍA}

Catálogo de ferias y fiestas. Estado de Puebla, Puebla, Secretaría de Turismo del Estado de Puebla [1998].

Dávila Padilla, Fray Agustín (O.P.), Historia de la fundación y discurso de la provincia de Santiago de México de la Orden de
Predicadores, 3a. ed., pról. de Agustín Millares Carlo, México, Academia Literaria, 1955.

«Diccionario católico» en Sagrada Biblia, Chicago, La Prensa Católica, 1958, págs. 1-314. (La obra tiene varias numeraciones de páginas. El «Diccionario...» aparece al final del libro con numeración independiente de páginas).

Glockner, Julio (comp.), Mirando el paraíso. Textos sobre Tonantzintla. Antologia, Puebla, Secretaría de Cultura del Gobierno del Estado de Puebla, 1995.

Iglesias y Cabrera, Sonia; Salazar Cárdenas, Leticia; Martínez Gómez, Julio César, La Semana Santa en México. Con la muerte en la cruz, México, Consejo Nacional para la Cultura y las Artes, 2002.

Lomelí Vanegas, Leonardo, Breve bistoria de Puebla, México, El Colegio de México Fondo de Cultura Económica, 2001.

Luna Parra, Adriana (coordinación general), Semana Santa en Iztapalapa, México, Departamento del Distrito Federal - Delegación Iztapalapa, Universidad Autónoma Metropolitana-Iztapalapa - El Juglar, 1992.

Rojas, Pedro, Tonantzintla, México, Universidad Nacional Autónoma de México, 1956.

Rubial García, Antonio, Santa Maria Tonantzintla, un pueblo, un templo, México, Universidad Iberoamericana, 1991.

Ruiz Moreno, Luisa, Santa María Tonantzintla. El relato en imagen, México, Consejo Nacional para la Cultura y las Artes, 1993. 